\title{
Hyperextension cervical spine injuries and traumatic central cord syndrome
}

\author{
Bizhan Aarabi, M.D., F.R.C.S.C., Michael Koltz, M.D., and David Ibrahimi, M.D. \\ Department of Neurosurgery, University of Maryland School of Medicine, Baltimore, Maryland
}

\begin{abstract}
Traumatic central cord syndrome (TCCS), regardless of its biomechanics, is the most frequently encountered incomplete spinal cord injury. Patients with TCCS present with disproportionate weakness of the upper extremities, and variable sensory loss and bladder dysfunction. Fractures and/or subluxations, forced hyperextension, and herniated nucleus pulposus are the main pathogenetic mechanisms of TCCS. Nearly $50 \%$ of patients with TCCS suffer from congenital or degenerative spinal stenosis and sustained their injuries during hyperextension as originally described by Schneider in 1954. Immunohistochemical and imaging studies indicate mild to moderate insult to axons and their ensheathing myelin in the lateral funiculi culminating in cytoskeletal injury and impaired conduction. More than one-half of these patients enjoy spontaneous recovery of motor weakness; however, as time goes on, lack of manual dexterity, neuropathic pain, spasticity, bladder dysfunction, and imbalance of gait render their activities of daily living nearly impossible. Based on the current level of evidence, there is no clear indication of the timing of decompression for relief of sustained spinal cord compression in hyperextension injuries. Future research, taking advantage of validated digital imaging data such as maximum canal compromise, maximum spinal cord compression, and lesion length on the CT and MR images, as well as more sensitive measures of bladder and hand function, spasticity, and neuropathic pain may help tailor surgery for a specific group of these patients. (DOI: 10.3171/FOC.2008.25.11.E9)
\end{abstract}

KEY WoRds • central cord syndrome $\quad$ cervical spine $\bullet$ spinal cord
spinal cord injury
$\bullet \quad$ trauma

$\mathrm{F}$ IRST reported by Thorburn ${ }^{71}$ in 1887 , the syndrome of TCCS was defined and popularized by Schneider in 1954..$^{56,58-60}$ Taylor, ${ }^{68}$ Taylor and Blackwood, ${ }^{69}$ and Schneider and colleagues ${ }^{56,58-60}$ related the syndrome to hyperextension of the cervical spine without concomitant fracture subluxations. Studies by Parke ${ }^{51}$ indicated a 2- to 3-mm canal compromise by hyperextension of the cervical spine due to overlapping of the laminae and the buckling of the ligamentum flavum. The share of TCCS among all the clinical syndromes following traumatic SCI is nearly $44 \% .{ }^{41}$ Approximately $35-58 \% \%^{2,11,18,26,32,66,79}$ of patients with TCCS are those with cervical spinal stenosis who injured their spinal cord without skeletal injury during hyperextension. Although these patients clearly experience continuous discoligamentous and osseous compression, the general trend since 1954 has been reluctance to undertake aggressive treatment and hasty decompression of the spinal cord in an urgent fashion. Lack of fracture or subluxations on insensitive imaging

Abbreviations used in this paper: ASIA = American Spinal Injury Association; LL = lesion length; $\mathrm{MCC}=$ maximum canal compromise; $\mathrm{MSCC}=$ maximum spinal cord compression; $\mathrm{SCI}=$ spinal cord injury; TCCS = traumatic central cord syndrome. studies, spontaneous functional recovery, comorbidities, and risk of intraoperative worsening of neurological condition have been some of the reasons preventing surgeons from relieving spinal cord compression as soon as possible. , $11,18,26,32,66$ This view is changing rapidly. Yamazaki et al. ${ }^{79}$ demonstrated a direct relationship between outcome and midsagittal diameter of the spinal canal. Validated clinical and imaging studies including the Subaxial Injury Classification scoring system, ${ }^{76}$ MCC, 31 MSCC, ${ }^{31}$ and $L^{2}{ }^{31}$ on MR imaging could offer powerful digital data to become more analytical, rather than descriptive, in pre- and postoperative definition of variables defining best ways to manage patients with TCCS due to hyperextension injuries. ${ }^{22,25,29,31,43,55,62,76}$

\section{Traumatic Central Cord Syndrome}

\section{Definition}

Traumatic cervical central cord syndrome is a partial SCI with disproportionate motor loss in the distal upper extremities and significant involvement of bladder function with variable degrees of sensory impairment below the level of skeletal injury. ${ }^{34,56,58-60}$ 


\section{B. Aarabi, M. Koltz, and D. Ibrahimi}

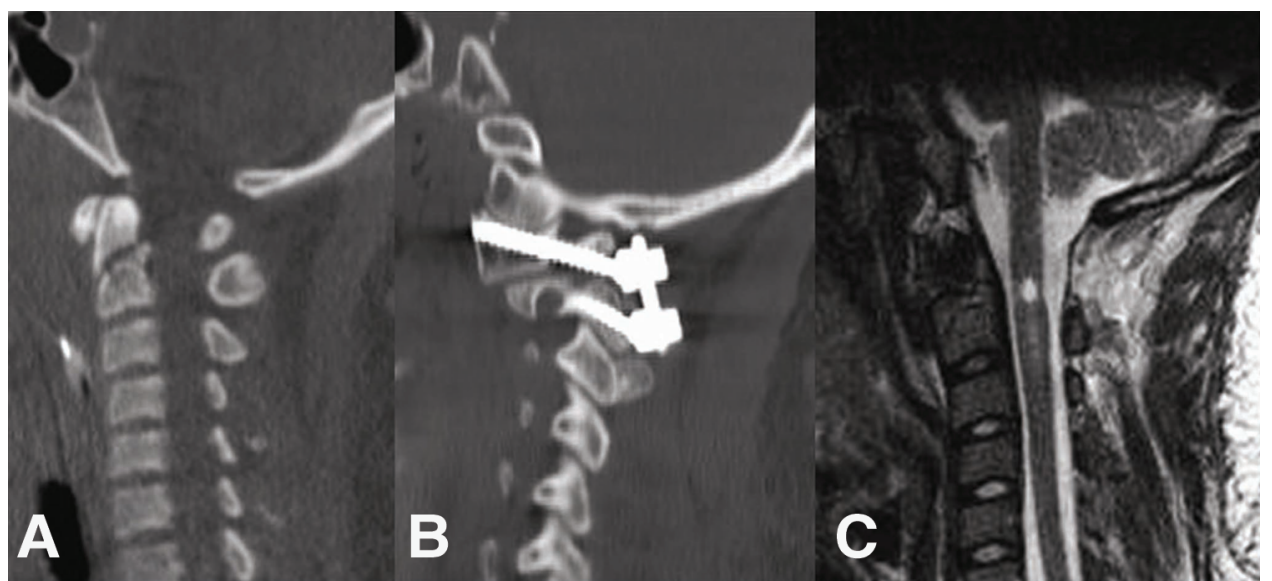

FIG. 1. Neuroimaging studies obtained in a 24-year-old woman with cruciate paralysis following a motor vehicle accident. A: Midsagittal reformatted CT of the cervical spine demonstrating a Type III odontoid fracture. B: Reformatted paramedian CT scan obtained immediately after surgery demonstrating surgical fusion of the C-1 lateral mass and C-2 pars interarticularis. C: Midsagittal T2-weighted image obtained 5 weeks postinjury indicating evidence of myelomalacia in the central part of spinal cord subjacent to the fracture. See text for more details.

\section{Correlative Neuroanatomy, Pathogenesis, and Pathology}

In primates, including man, the descending motor pathways of the corticospinal tracts pass through the internal capsule and midbrain keeping their discrete somatotopic organization. Beyond the midbrain, however, the somatotopic organization of the corticospinal tract is not discrete, leading to confusion as to the exact anatomical substrate for cruciate paralysis and TCCS. $5,20,49,50$

For years, the presumed explanation of cruciate paralysis by Wallenberg ${ }^{77}$ and Bell ${ }^{7,8}$ seemed quite logical. According to their suggestions, based on their clinical studies, corticospinal fibers serving the upper extremities were anatomically segregated in the region of the pyramidal decussation, with the upper extremity fibers being rostral and near the midline and the lower extremity fibers caudal and lateral. It was presumed, although never anatomically proven, that focal injury to the upper extremity corticospinal tract fibers near the cervicomedullary junction could produce weakness of the upper extremities, hence "cruciate paralysis." The images in Fig. 1 were obtained in a 24-year-old woman with a Type III odontoid fracture and classic cruciate paralysis. At admission her ASIA motor score in the upper extremities was 2/50 and in the lower extremities 13/50. Eight months later, her ASIA motor score in the upper extremities was $25 / 50$ and in the lower extremities 50/50. She was hyperreflexic, had no difficulty with bladder function, and was able to walk independently.

Foerster ${ }^{30}$ and Schneider et al. ${ }^{56-58,61}$ presumed a similar analogy in the pathogenesis of TCCS. The assumption was that corticospinal tract fibers subserving the upper extremities were layered more centrally and therefore were involved by a hematomyelic cavity producing weakness of the upper extremities while peripherally located fibers, innervating the muscles of the lower extremities, remained intact (Fig. 2). ${ }^{16}$ The MR image in Fig. 3 was obtained in an 85-year-old patient who had TCCS following a hyperextension injury. Signal change is evident at the level of C3-4 and distractive extension Stage 1 at C6-7.
Several recent lines of evidence indicate that the assumptions of Wallenberg, ${ }^{77}$ Bell, ${ }^{7,8}$ Foerester, ${ }^{30}$ and Schneider and colleagues ${ }^{56-58,61}$ need to be modified. Tracing studies of Pappas et al. ${ }^{49}$ and Marchi degeneration studies of Coxe and Landau ${ }^{20}$ and Barnard and Woolsey ${ }^{5}$ in monkeys indicate no somatotopic organization of the corticospinal tracts at the level of pyramids or cervical spinal cord (Fig. 4). Studies of Nathan and colleagues ${ }^{44-46}$ in human patients tend to confirm the findings of previous investigators.

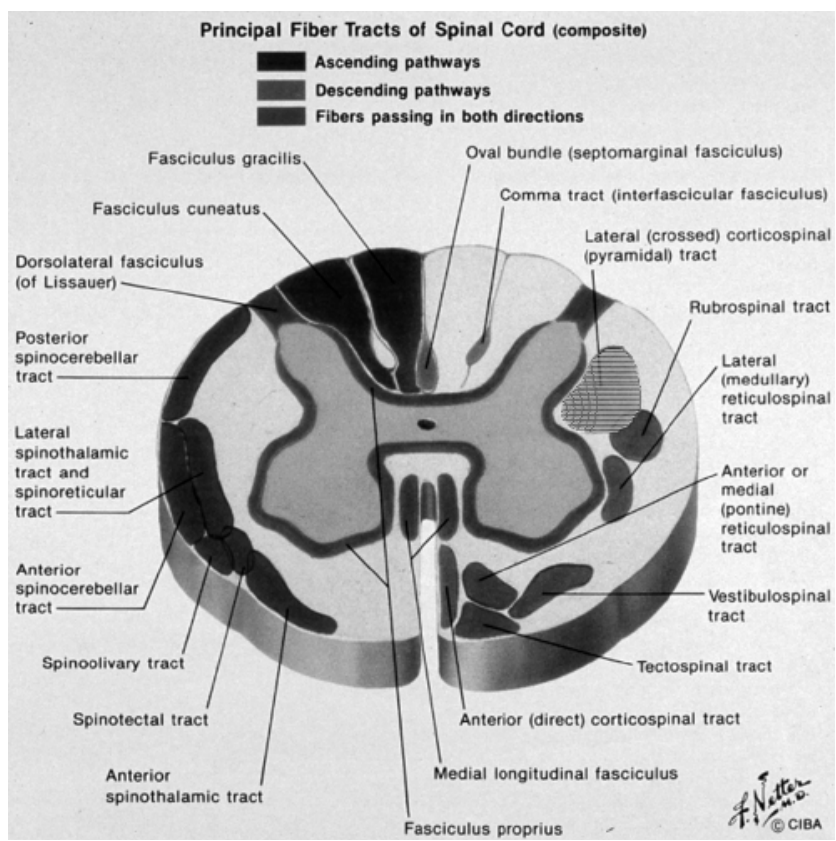

FIG. 2. Modified schematic transverse section of the cervical spinal cord indicating ascending sensory and descending motor pathways. Hatched left corticospinal tract indicates the presumed concentric layering of the corticospinal tract as proposed by Foerster and Schneider to explain TCCS. Modified from Jones: Netter's Neurology. Used with permission of Elsevier, Inc. All rights reserved. 


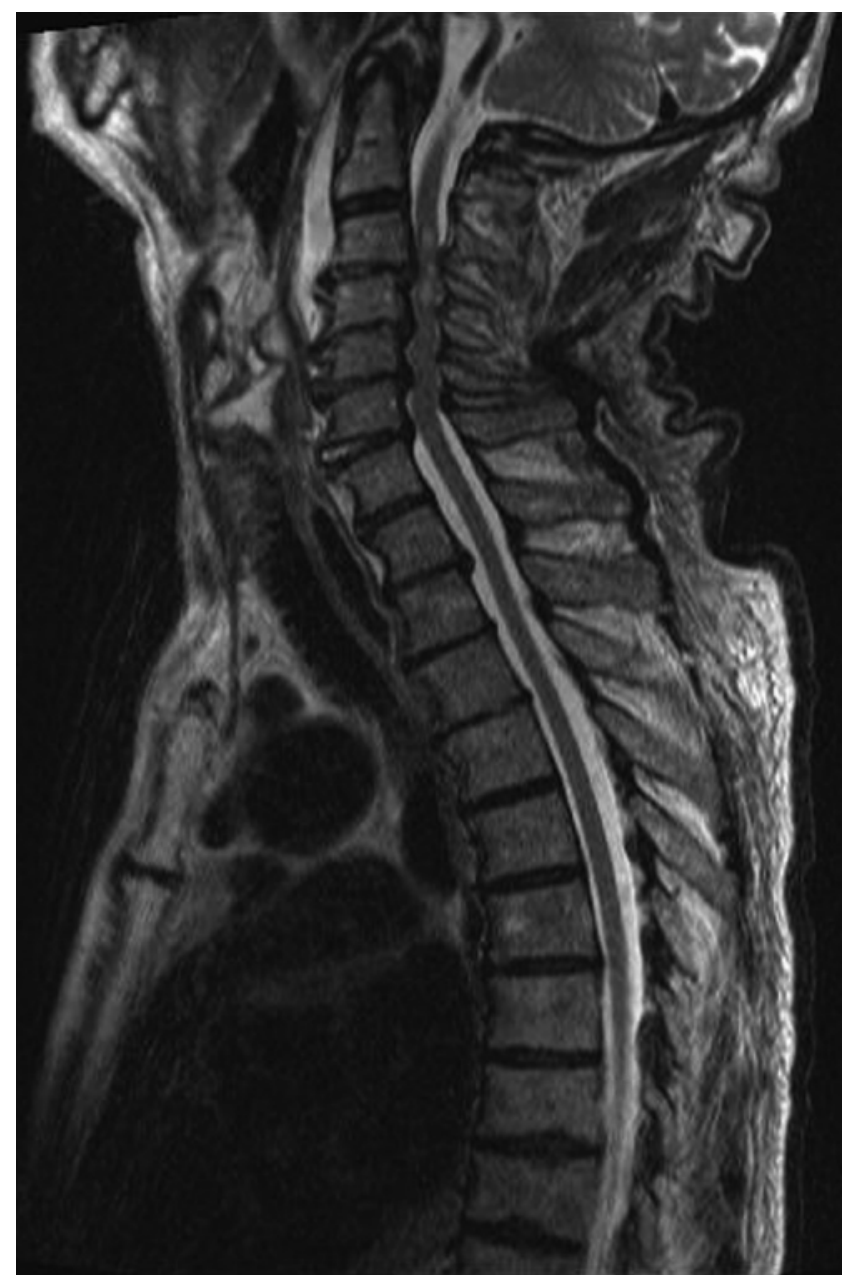

FIG. 3. Midsagittal reformatted T2-weighted MR image obtained in an 85-year-old man after a fall and clinical presentation of TCCS. The patient's ASIA motor score at admission was 22. The image demonstrates spinal stenosis, signal change at $\mathrm{C} 3-4$, and distractive extension injury at $\mathrm{C} 6-7$.

Correlating necropsy studies with MR imaging findings by Jimenez et al., ${ }^{35}$ Martin et al., ${ }^{40}$ and Quencer et al. ${ }^{53}$ proved that in the majority of patients with central cord syndrome, there is no evidence of hematomyelia or significant injury to the central gray matter. Axonal disruption and swelling is widespread in the white matter of the lateral funiculi and to a lesser extent the posterior columns.

Recent experimental studies have indicated that complete unilateral or bilateral transection of the corticospinal tracts at the level of the pyramids or cerebral peduncles renders monkeys only partially paralyzed with hand function more severely affected. As in patients with TCCS, recovery of function in these monkeys starts from the lower extremities, then proceeds to the proximal upper extremities and at last the fingers. ${ }^{14,15,37,38,63,73}$

An alternative hypothesis proposed by Levi et al. ${ }^{39}$ and Collignon et al..$^{19}$ is that the 2 syndromes of cruciate paralysis and TCCS may result from pathological entities affecting the corticospinal tracts anywhere from the pyramids to the cervical enlargement. It is suggested that the corticospinal tracts primarily subserve fine motor movements to the distal musculature, especially the upper limbs. Preservation of leg movement is mediated by other descending motor pathways important for locomotion.

Lesions in patients presenting with TCCS seem to comprise 3 main categories: 1) cervical spondylosis associated with segmental spinal stenosis or interspace disc/osteophyte complex; 2) fracture subluxations; and 3) sequestrated disc without evidence of spinal stenosis. $2,11,13,18,26,32,42,54,66,72,79$ The proportion of each of these pathological processes in each case series is different, reflecting the nature of the studies, which are mostly uncontrolled and retrospective. In the study of Aito et al., ${ }^{2}$ 44 of 82 patients with TCCS had hyperextension injuries and the rest had fracture/subluxations or disc injury or SCI without evidence of trauma. Nineteen of 28 patients in the study of Bose et al. ${ }^{11}$ had hyperextension injuries and the condition of 14 of 28 was stable according to the principals of White et al. ${ }^{78}$ In Chen and colleagues' ${ }^{18}$ study of surgical treatment of TCCS,16 of 28 patients had fracture subluxations or disc herniation and 12 had disc/osteophyte complex. In the series of TCCS cases reported by Dvorak et al., ${ }^{26} 43$ of 70 patients with adequate follow-ups had fracture/subluxations, 25 had spinal stenosis, and 2 had ruptured discs. In 2002 Guest et al. ${ }^{32}$ evaluated early versus late surgery in 50 patients with TCCS who presented to Barrow Neurological Institute.Their retrospective study included 24 patients (48\%) with spinal stenosis, 10 (20\%) with fracture subluxations, and $16(32 \%)$ with herniated discs. Between May 2007 and June 1, 2008, 42 patients with TCCS admitted to the Shock Trauma Center in Baltimore were screened for eligibility for a randomized prospective trial evaluating early (first 5 days) versus late (6 \pm 1 weeks) spinal cord decompression (unpublished data). Twenty (48\%) of 42 patients had either spinal stenosis or disc/osteophyte complex, 13 (33\%) had fracture subluxations, $5(12 \%)$ sequestrated disc, and $3(7 \%)$ SCI without radiological abnormality. Twelve of 20 patients with spinal stenosis also had concomitant distractive extension injury Stage 1 (Fig. 3). The C3-4 level, either by itself or in conjunction with other levels, was the most frequent level causing spinal cord compression (noted in 8 patients). It was not unusual that the site of compression was associated with a remote site of distractive extension injury.

\section{The Syndrome}

Demographic data indicate that middle-aged men are more susceptible to injuries producing TCCS. In several recent series the proportion of men ranged from 56.2 to $88 \% .2,11,18,26,32,74,79$ This tendency is even more pronounced in reports of case series describing hyperextension injuries. Aito et al. ${ }^{2}$ reported on a series of 44 cases managed conservatively; the patients had TCCS without radiological evidence of fracture dislocations and their mean age was 56. The mean age of patients in the case series of Dvorak et al., ${ }^{26}$ Guest et al., ${ }^{32}$ Yamazaki et al. ${ }^{79}$ and Uribe et al..$^{74}$ were $51,62,56.2$, and 56 years, respectively. Very few investigators have systematically studied their patients at the time of admission using the ASIA motor function assessment system. It is not unusual for patients to experience quadriplegia immediately after an accident 

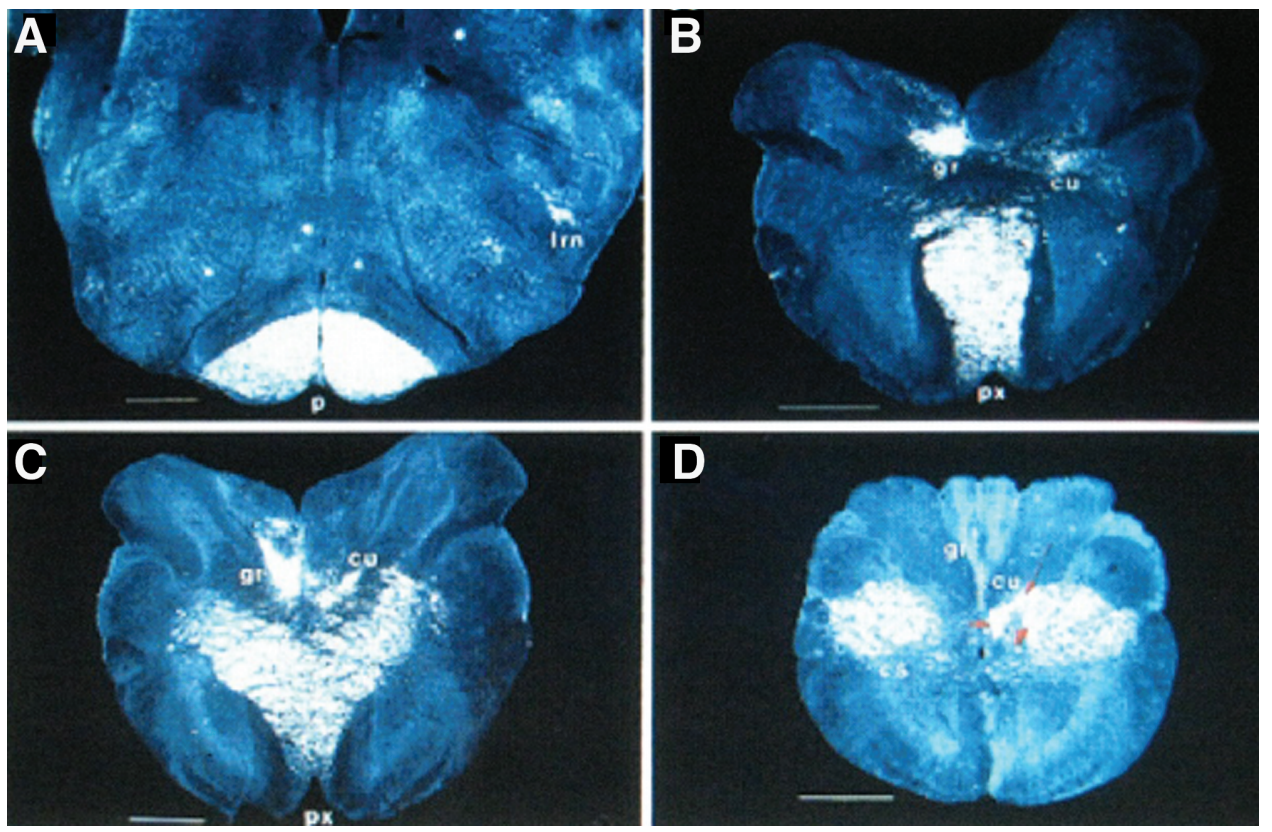

FIG. 4. Photographs of sections from the brain of a squirrel monkey following injection of $0.05 \mu \mathrm{l} 2 \%$ wheat germ agglutinin conjugated with horseradish peroxidase in the foot region of the left and hand region of the right hemisphere precentral cortex. The sections were reacted with tetramethylbenzidine and then stained with neutral red, mounted, and examined with polarizedlight microscopy. A: Transverse section through the medulla at the level of the inferior olive. The evenness in the fiber labeling of the pyramids is easily seen. Fine fibers leaving the pyramids (p) on the left side correspond to the forelimb injection and cross the brainstem to terminate the lateral reticular formation (Irn). Bar $=1 \mathrm{~mm} . \quad B$ : Transverse section through the rostral part of the pyramidal decussation. Heavy terminal labeling is visible in the gracile nucleus ( $\mathrm{gr}$ ) on the left while more scattered labeling is seen in and around the cuneate nucleus (cu) on the right. The pyramidal tracts (px) are decussating symmetrically. Bar $=1 \mathrm{~mm}$. C: A slightly more caudal section than shown in C, but still in the pyramidal decussation. The gracile nucleus is still heavily labeled; the labeling in the cuneate nucleus has become more focused and has shifted medially. Decussating pyramidal fibers have moved dorsally and laterally but still occupy symmetrical positions in their respective halves of the brainstem. Bar $=1 \mathrm{~mm}$. D: Transverse section immediately caudal to the pyramidal decussation. The labeled corticospinal (cs) tracts form roughly circular patterns that occupy symmetrical areas on both sides. The gracile labeling is largely absent, while the cuneate labeling is dense and sharply defined. A second area of corticospinal termination (curved arrow) is visible on the medial border of the right corticospinal tract. This area lies in Kuypers' internuncial region. Some of the corticospinal terminals are present in the cuneate nucleus (long arrow) and the rest are in the central gray area (short arrow). Bar $=1 \mathrm{~mm}$. Modified from Pappas et al.: J Neurosurg 75:935-940, 1991, with permission.

and to recover gradually so that by the time they arrive at the emergency department they are complaining of weakness and an extreme burning sensation of the arms and hands, which is very uncomfortable upon touch. The admission ASIA motor score for all the 14 conservatively treated patients in the case series reported by Bose et al. ${ }^{11}$ was 50.6 and for those managed surgically it was 58.5 . In the case series reported by Guest et al., ${ }^{32}$ the ASIA motor scores for patients who did not have fractures and who were treated surgically less than 24 hours and more than 24 hours after injury were 56.8 and 61.7, respectively. Among the 42 previously mentioned patients with TCCS admitted to our center and screened for enrollment in the randomized trial of the timing of surgery, the mean ASIA motor score was 77 .

\section{Imaging Studies}

Computed tomography and MR imaging studies of the cervical spine and, when indicated, dynamic studies will essentially rule out the possibility of skeletal damage, discoligamentous injuries, and hidden fractures. ${ }^{1,3,4,6,9,10,21,23,24,33,36,64,67,70,75}$ New technology even en- ables us to measure the degree of canal compromise and the extent of spinal cord compression. ${ }^{29,31,43,55}$ (Figs. 5, 6, and 7).

\section{Management}

Class II and III evidence support early surgical intervention in TCCS due to herniated nucleus pulposus and unstable skeletal injuries. The objectives behind this approach are spinal cord decompression, alignment and internal fixation, and thus interruption and/or prevention of further secondary insults. This concept is not universally accepted in stable TCCS due to forced hyperextension superimposed on spinal stenosis. Spontaneous recovery of function, comorbidities, lack of proved instability, and a less aggressive approach recommended by surgeons on the basis of the experience of Schneider and colleagues are only a few reasons. ${ }^{2,11-13,17,25,26,32-34,42,47,54,56-58,60,61,65,66,74,79}$ In 2007, Aito et al. ${ }^{2}$ compared long-term motor and functional recovery, including ASIA impairment scale, Walking Index for Spinal Cord Injury, and Functional Independent Scale (FIM) scores of 38 patients treated surgically and 44 patients who were treated conservatively. The 


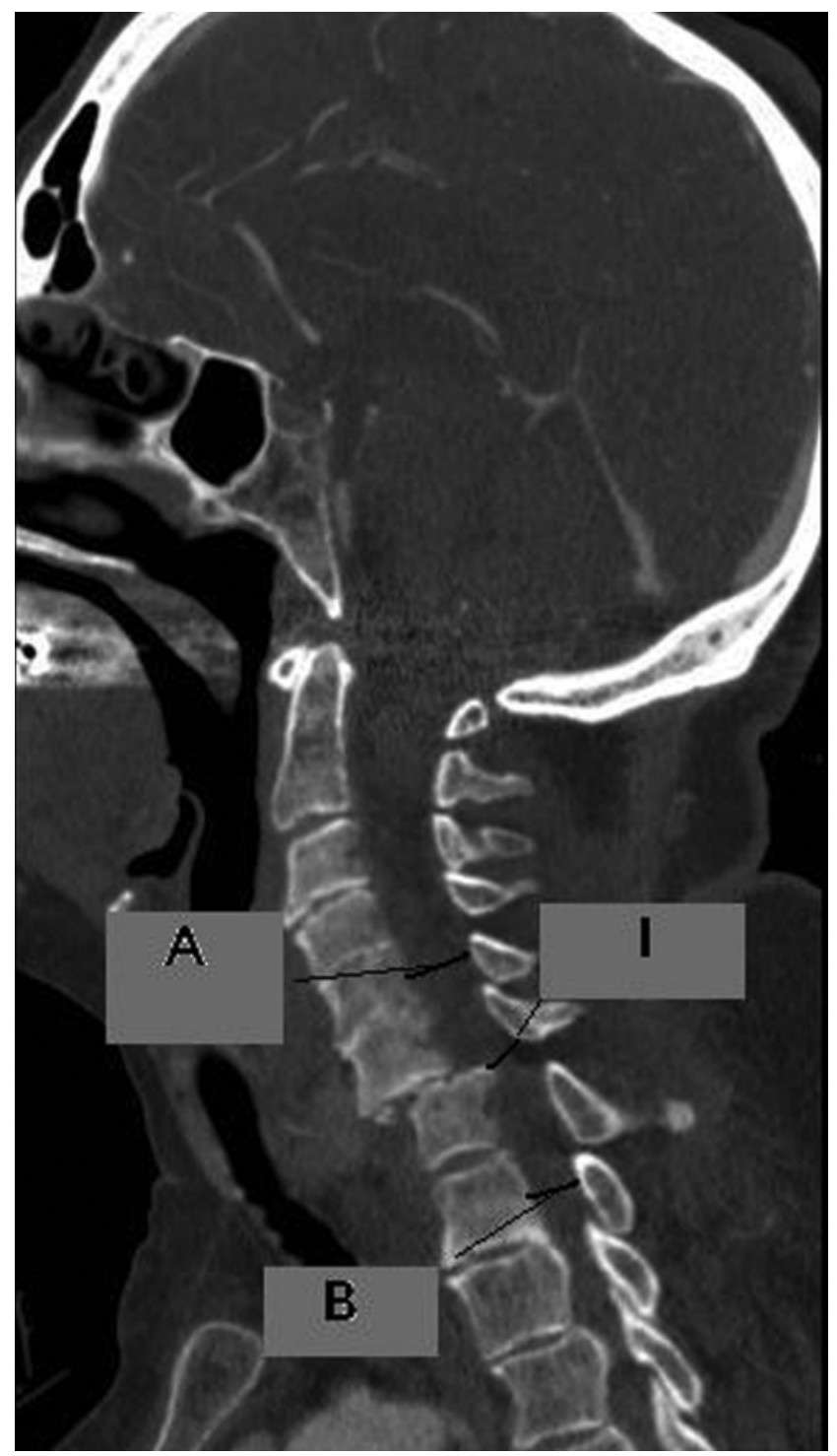

FIG. 5. Measurement of MCC following distractive flexion injury. $A=$ midsagittal diameter 2 segments above the site of injury; $\mid$ = midsagittal diameter at the level of injury; $B=$ midsagittal diameter 2 segments below the site of injury. MCC $(\%)=[1-I /(A+B) / 2] \times 100$. (See Furlan et al.)

conservative-treatment group suffered hyperextension injuries and the surgical-treatment group skeletal and discoligamentous injuries. The authors noted no statistically significant difference in functional outcome between the 2 groups. In 1984, Bose et al. ${ }^{11}$ from Thomas Jefferson University compared 2 groups of patients with TCCS14 patients whose condition was unstable and who were treated surgically, and 14 patients whose condition was stable and who were treated conservatively; they noted better motor scores in the surgically treated group. The authors concluded that operative intervention was safe and when chosen properly could result in better motor recovery. In 2002, Guest et al. ${ }^{32}$ reviewed their experience with TCCS at Barrow Neurological Institute. In 2 groups of surgically treated patients, early surgery (within 24 hours of injury) was compared with late surgery ( $>24$ hours after injury). The conclusion was that early surgery

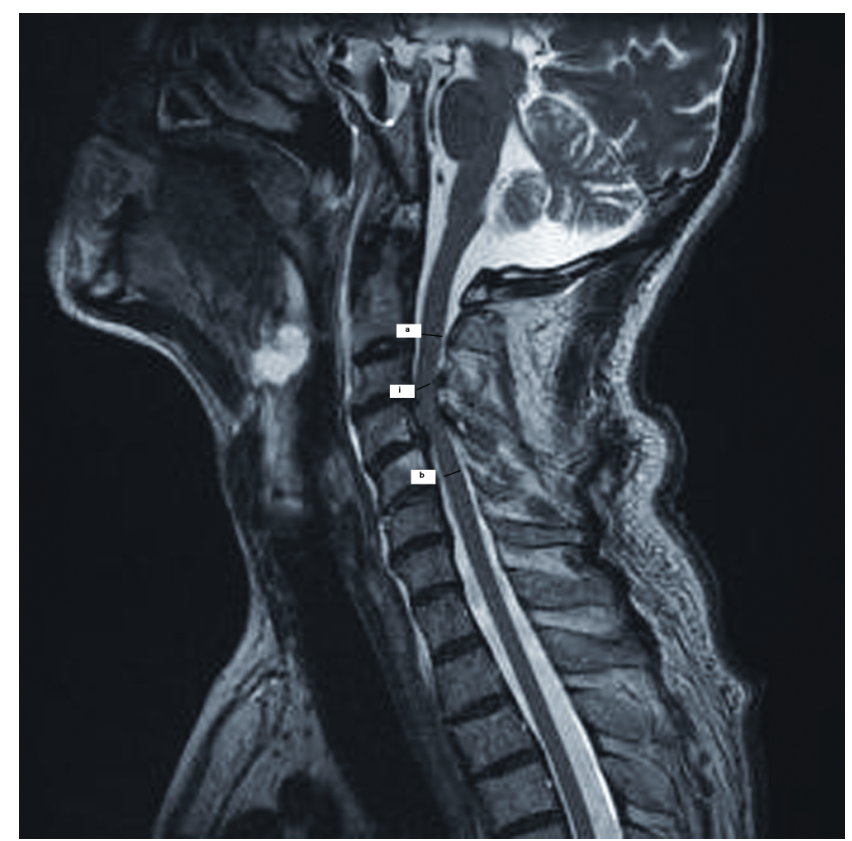

FIG. 6. Measurement of MSCC following TCCS. a = spinal cord diameter on T2-weighted images at 2 cord segments above the injury; i $=$ spinal cord diameter at the level of injury; $b=$ spinal cord diameter 2 segment below the level of injury. MSSC $(\%)=[1-i /(a+b) / 2] \times 100$. (For more information, see Furlan et al.)

in patients with skeletal injuries or disc herniation resulted in better motor recovery. The timing of surgery did not affect motor recovery in patients suffering from spinal stenosis. Patients older than 60 years and those with bladder dysfunction fared worse than younger patients without bladder dysfunction at the time of admission. Younger patients with TCCS seem to do better than older patients. ${ }^{32,52}$ In 2005, Yamazaki et al. ${ }^{79}$ analyzed their experience with 47 patients with spinal stenosis and found a significant relationship between the sagittal diameter of the spine and functional outcome. Evidence is accumulating that earlier decompression of a compressed spinal cord in traumatic spinal cord injuries is safe and may in fact promote recovery of function..$^{28,48}$ Preliminary results of a prospective multicenter trial to evaluate the role and timing of decompression in patients with cervical SCI reported by Fehlings et al. ${ }^{27}$ indicated better functional outcome when the spinal cord was decompressed within 24 hours of injury as compared with decompression after 24 hours of trauma. Although patients with TCCS were included in the study, the exact influence of the timing of decompression on hyperextension injuries remains to be elucidated.

What approach should be taken for spinal cord decompression in patients with hyperextension injuries is not well established..$^{11,13,25,28,32,33,48,74,79}$ In a recent review of the current literature, Dvorak et al. ${ }^{25}$ were not able to establish a standard algorithm for management of subaxial cervical spine injuries. Based on the Subaxial Injury Classification $^{76}$ classification system, the options were as follows. In patients with normal-looking sagittal balance of the cervical spine, laminectomy with or without internal 


\section{B. Aarabi, M. Koltz, and D. Ibrahimi}
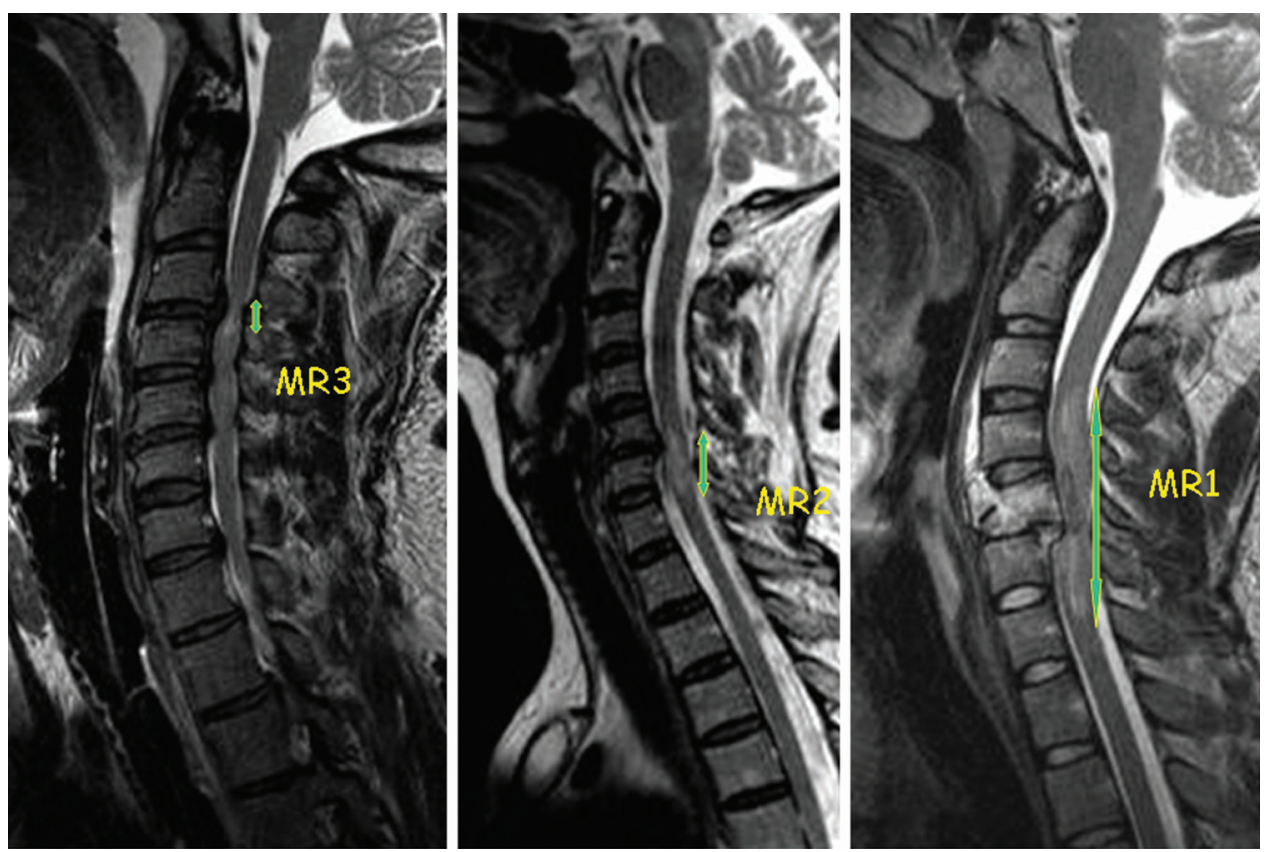

FIG. 7. Measurement of LL on T2-weighted MR images in $\mathrm{mm}$. Type 1 injury is defined as any injury with bleeding inside the spinal cord, Type 2 is defined high signal without bleeding and more than one skeletal segment in length, and Type 3 is defined as high signal without evidence of bleeding confined to 1 skeletal segment. (For details, see Furlan et al. ${ }^{31}$ and Schaefer et al., 1992.)

fixation is an option, but in patients with a straight cervical spine or kyphotic deformity, surgical decompression should be from multilevel discectomy or corpectomy followed by internal fixation.

\section{Conclusions}

Traumatic central cord syndrome is the most frequent syndrome encountered after an incomplete cervical SCI. Almost $50 \%$ of all cases of TCCS are due to hyperextension injuries involving old male patients and usually due to a fall. Advanced age, comorbidities, spontaneous recovery of function, and a negative outlook toward surgery make any sort of recommendation for the timing of surgery at the level of an option. Future research should be multicenter, prospective, and analytical rather than descriptive, taking advantages of digital data, such as MCC, ${ }^{31} \mathrm{MSCC}^{,{ }^{31}} \mathrm{LL}^{31}$ and midsagittal diameter ${ }^{31,79}$ to define variables best fit for surgery and prediction of treatment effect.

\section{Disclosure}

This work was supported by a grant from the Maryland State Department of Health and Human Services (Protocol H-28962).

\section{Disclaimer}

The authors report no conflict of interest concerning the materials or methods used in this study or the findings specified in this paper.

\section{References}

1. Aarabi B, Neal CJ, Philp A: Special considerations in the evaluation of patients with combined head and spinal injuries and multiple system trauma, in Loftus CM (ed): Neurosurgical Emergencies, ed 2. New York, NY: AANS/Thieme, pp 159-171, 2008

2. Aito S, D’Andrea M, Werhagen L, Farsetti L, Cappelli S, Bandini B, et al: Neurological and functional outcome in traumatic central cord syndrome. Spinal Cord 45:292-297, 2006.

3. Ajani AE, Cooper DJ, Scheinkestel CD, Laidlaw J, Tuxen DV: Optimal assessment of cervical spine trauma in critically ill patients: a prospective evaluation. Anaesth Intensive Care 26:487-491, 1999

4. Banit DM, Grau G, Fisher JR: Evaluation of the acute cervical spine: a management algorithm. J Trauma 49:450-456, 2000

5. Barnard JW, Woolsey CN: A study of localization in the cortico-spinal tracts of monkey and rat. J Comp Neurol 105:2550,1956

6. Bayless P, Ray VG: Incidence of cervical spine injuries in association with blunt head trauma. Am J Emerg Med 7:139142, 1989

7. Bell HS: Paralysis of both arms from injury of the upper portion of the pyramidal decussation: "cruciate paralysis". J Neurosurg 33:376-380, 1970

8. Bell HS: Cruciate paralysis, in Vinken PJ, Bruyn GW (eds): Injuries of the Spine and Spinal Cord: Handbook of clinical Neurology, Vol 25. Amsterdam: North Holland Publishing Company, pp 391-392, 1976

9. Benzel EC, Hart BL, Ball PA, Baldwin NG, Orrison WW, Espinosa MC: Magnetic resonance imaging for the evaluation of patients with occult cervical spine injury. J Neurosurg 85:824-829, 1996

10. Berne JD, Velmahos GC, El-Tawil Q, Demetriades D, Asensio JA, Murray JA, et al: Value of complete cervical helical computed tomographic scanning in identifying cervical spine injury in the unevaluable blunt trauma patient with multiple injuries: a prospective study. J Trauma 47:896902, 1999

11. Bose B, Northrup BE, Osterholm Jl, Cotler JM, DiTunno JF: 
Reanalysis of central cervicalcord injury management. Neurosurgery 15:367-372, 1984

12. Bridle MJ, Lynch KB, Quesenberry CM: Long term function following the central cervical cord syndrome. Paraplegia 28:178-185, 1990

13. Brodkey JS, Miller CF Jr, Harmody RM: The syndrome of acute central cervical spinal cord injury revisited. Surg Neurol 14:251-257, 1980

14. Bucy PC: Is there a pyramidal tract? Brain 80:376-392, 1957

15. Bucy PC, Keplinger JE, Siqueira EB: Destruction of the "Pyramidal Tract" in man. J Neurosurg 21:285-298, 1964

16. Camac A, Jones HR Jr: Anatomical aspects of myelopathies, in Royden H, Jones HR Jr (eds): Netter's Neurology. Philadelphia, PA, W. B. Saunders Publishing, pp 492-502, 2005

17. Chen TY, Dickman CA, Eleraky M, Sonntag VK: The role of decompression for acute incomplete cervical spinal cord injury in cervical spondylosis. Spine 23:2398-2403, 1998

18. Chen TY, Lee ST, Lui TN, Wong CW, Yeh YS, Tzaan WC, et al: Efficacy of surgical treatment in traumatic central cord syndrome. Surg Neurol 48:435-440, 1997

19. Collignon F, Martin D, Lenelle J, Stevenaert A: Acute traumatic central cord syndrome: magnetic resonance imaging and clinical observations. J Neurosurg 96:29-33, 2002

20. Coxe WS, Landau WM: Patterns of Marchi degeneration in the monkey pyramidal tract following small discrete cortical lesions. Neurology 20:89-100, 1970

21. D’Alise MD, Benzel EC, Hart BL: Magnetic resonance imaging evaluation of the cervical spine in the comatose or obtunded trauma patient. J Neurosurg 91 (1 Suppl):54-59, 1999

22. Dai L: Magnetic resonance imaging of acute central cord syndrome: correlation with prognosis. Chin Med Sci J 16:107110,2001

23. Davis JW, Parks SN, Detlefs CL, Williams GG, Williams JL, Smith RW: Clearing the cervical spine in obtunded patients: the use of dynamic fluoroscopy. J Trauma 39:435-438, 1995

24. Davis JW, Phreaner DL, Hoyt DB, Mackersie RC: The etiology of missed cervical spine injuries. J Trauma 34:342-346, 1993

25. Dvorak MF, Fisher CG, Fehlings MG, Rampersaud YR, Oner FC, Aarabi B, et al: The surgical approach to subaxial cervical spine injuries: an evidence-based algorithm based on the SLIC classification system. Spine 32:2620-2629, 2007

26. Dvorak MF, Fisher CG, Hoekema J, Boyd M, Noonan V, Wing $\mathrm{PC}$, et al: Factors predicting motor recovery and functional outcome after traumatic central cord syndrome: a long-term follow-up. Spine 30:2303-2311, 2006

27. Fehlings MG, Vaccaro A, Aarabi B, Shaffrey C, Harrop J, Dvorak M: A prospective, multicenter trial to evaluate the role and timing of decompression in patients with cervical spinal cord injury: Initial one year results of the STASCIS Study.. J Neurosurg 104:A848, 2008 (Abstract)

28. Fehlings MG, Perrin RG: The role and timing of early decompression for cervical spinal cord injury: update with a review of recent clinical evidence. Injury 36:B13-B26, 2005

29. Flanders AE, Schaefer DM, Doan HT, Mishkin MM, Gonzalez CF, Northrup BE: Acute cervical spine trauma: correlation of MR imaging findings with degree of neurologic deficit. Radiology 177:25-33, 1990

30. Foerster O: Symptomatologie der Erkrankungen des Ruckenmarks und seiner Wurzeln, in Bumke O, Foerster O (eds): Handbook of Neurology, Vol 5. Berlin: Springer, p 83, 1936

31. Furlan JC, Fehlings MG, Massicotte EM, Aarabi B, Vaccaro $\mathrm{AR}$, Bono CM, et al: A quantitative and reproducible method to assess cord compression and canal stenosis after cervical spine trauma: a study of interrater and intrarater reliability. Spine 32:2083-2091, 2007
32. Guest J, Eleraky MA, Apostolides PJ, Dickman CA, Sonntag VK: Traumatic central cord syndrome: results of surgical management. J Neurosurg 97 (1 Suppl):25-32, 2002

33. Hadley MN, Walters BC, Grabb PA, Oyesiku NM, Prezybylski GJ, Resnick DK, et al: Guidelines for the Management of Acute Cervical Spine and Spinal Cord injuries. Clin Neurosurg 49:407-498, 2002

34. Harrop JS, Sharan A, Ratliff J: Central cord injury: pathophysiology, management, and outcomes. Spine J 6:198S-206S, 2006

35. Jimenez O, Marcillo A, Levi AD: A histopathological analysis of the human cervical spinal cord in patients with acute traumatic central cord syndrome. Spinal Cord 38:532-537, 2000

36. Klein GR, Vaccaro AR, Albert TJ, Schweitzer M, Deely D, Karasick D, et al: Efficacy of magnetic resonance imaging in the evaluation of posterior cervical spine fractures. Spine 24:771-774, 1999

37. Lawrence DG, Kuypers HG: The functional organization of the motor system in the monkey. I. The effects of bilateral pyramidal lesions. Brain 91:1-14, 1968

38. Lawrence DG, Kuypers HG: The functional organization of the motor system in the monkey: II. The effects of lesions of the descending brain stem pathways. Brain 91:15-36, 1968

39. Levi A, Tator $\mathrm{CH}$, Bunge RP: Clinical Syndromes associated with disproportionate weakness of the upper versus lower extremities after cervical spinal cord injury. Neurosurgery 38:179-185, 1996

40. Martin D, Schoenen J, Lenelle J, Reznik M, Moonen G: MRIpathological correlations in acute traumatic central cord syndrome: case report. Neuroradiology 34:262-266, 1992

41. McKinley W, Santos K, Meade M, Brooke K: Incidence and outcomes of spinal cord injury clinical syndromes. J Spinal Cord Med 30:215-224, 2007

42. Merriam WF, Taylor TK, Ruff SJ, McPhail MJ: A reappraisal of acute traumatic central cord syndrome. J Bone Joint Surg Br 68:708-713, 1986

43. Miyanji F, Furlan JC, Aarabi B, Arnold PM, Fehlings MG: Acute cervical traumatic spinal cord Injury: MR imaging findings correlated with neurologic outcome - prospective study with 100 consecutive patients. Radiology 243:820827, 2007

44. Nathan PW: Effects on movement of surgical incisions into the human spinal cord. Brain 117:337-346, 1994

45. Nathan PW, Smith MC: Long descending tracts in man. I. Review of present knowledge. Brain 78:248-303, 1955

46. Nathan PW, Smith MC, Deacon P: The corticospinal tracts in man. Course and location of fibres at different segmental levels. Brain 113:303-324, 1990

47. Newey ML, Sen PK, Fraser RD: The long-term outcome after central cord syndrome: a study of the natural history. J Bone Joint Surg Br 82:851-855, 2000

48. Papadopoulos SM, Selden NR, Quint DJ, Patel N, Gillespie $\mathrm{B}$, Grube S: Immediate spinal cord decompression for cervical spinal cord injury: feasibility and outcome. J Trauma 52:323-332, 2002

49. Pappas CT, Gibson AR, Sonntag VK: Decussation of hindlimb and fore-limb fibers in the monkey corticospinal tract: relevance to cruciate paralysis. J Neurosurg 75:935-940, 1991

50. Parent A, Carpenter MB: Carpenter's Human Neuroanatomy. Baltimore, MD: Williams \& Wilkins, 1983

51. Parke WW: Correlative anatomy of cervical spondylotic myelopathy. Spine 13:831-837, 1988

52. Penrod LE, Hegde SK, Ditunno JF Jr: Age effect on prognosis for functional recovery in acute traumatic central cord syndrome. Arch Phys Med Rehabil 71:963-968, 1990

53. Quencer RM, Bunge RP, Egnor M, Green BA, Puckett W, Naidich TP, et al: Acute traumatic central cord syndrome: 


\section{B. Aarabi, M. Koltz, and D. Ibrahimi}

MRI-pathological correlations. Neuroradiology 34:85-94, 1992

54. Roth EJ, Lawler MH, Yarkony GM: Traumatic central cord syndrome: clinical features and functional outcomes. Arch Phys Med Rehabil 71:18-23, 1990

55. Schaefer DM, Flanders AE, Osterholm JL, et al: Prognostic significance of magnetic resonance imaging in the acute phase of cervical spine injury. J Neurosurg 76:218-223, 1992

56. Schneider RC: A syndrome in acute cervical spine injuries for which early operation is indicated. J Neurosurg 8:360-367, 1951

57. Schneider RC, Cherry G, Pantek H: The syndrome of acute central cervical spinal cord injury. J Neurosurg 13:546-577, 1954

58. Schneider RC, Crosby EC, Russo RH, Gosch HH: Traumatic spinal cord syndromes and their management. Clin Neurosurg 20:424-449, 1973

59. Schneider RC, McGillicuddy JE: Concomitant craniocerebral and spinal trauma with special reference to the cervicomedullary region, in Vinken PJ, Bruyn GW (eds): Injuries of the Brain and Skull: Handbook of Clinical Neurology, Vol 24. Amsterdam: North Holland Publishing Company, pp 149-152, 1976

60. Schneider RC, Schemm GW: Vertebral artery insufficiency in acute and chronic spinal trauma. J Neurosurg 18:348-360, 1961

61. Schneider RC, Thompson JC, Bebin J: The syndrome of acute central cervical spinal cord injury. J Neurol Neurosurg Psychiatry 21:216-227, 1958

62. Schuster R, Waxman K, Sanchez B, Becerra S, Chung R, Conner S, et al: Magnetic resonance imaging is not needed to clear cervical spines in blunt trauma patients with normal computed tomographic results and no motor deficits. Arch Surg 140:762-766, 2005

63. Schwartzman RJ: A behavioral analysis of complete unilateral section of the pyramidal tract at the medullary level in Macaca mulatta. Ann Neurol 4:234-244, 1978

64. Sees DW, Rodriguez Cruz LR, Flaherty SF, Ciceri DP: The use of bedside fluoroscopy to evaluate the cervical spine in obtunded trauma patients. J Trauma 45:768-771, 1998

65. Shrosbree RD: Acute central cervical spinal cord syndrome: Aetiology, age incidence and relationship to the orthopedic injury. Paraplegia 14:251-258, 1977

66. Song J, Mizuno J, Nakagawa H, Inoue T: Surgery for acute subaxial traumatic central cord syndrome without fracture or dislocation. J Clin Neurosci 12:438-443, 2005

67. Tan E, Schweitzer ME, Vaccaro L, Spetell AC: Is computed tomography of nonvisualized C7-T1 cost-effective? J Spinal Disord 12:472-476, 1999
68. Taylor AR: The mechanism of injury to the spinal cord in the neck without damage to the vertebral column. J Bone Joint Surg Br 33:543-547, 1951

69. Taylor AR, Blackwood W: Paraplegia in hyperextension cervical injuries with normal radiographic appearance. J Bone Joint Surg Br 30:245-248, 1948

70. Tehranzadeh J, Bonk RT, Ansari A, Mesgarzadeh M: Efficacy of limited CT for nonvisualized lower cervical spine in patients with blunt trauma. Skeletal Radiol 23:349-352, 1994

71. Thorburn W: Cases on injury to the cervical region of the spinal cord. Brain 9:510-543, 1887

72. Tow AM, Kong KH: Central cord syndrome: functional outcome after rehabilitation. Spinal Cord 36:156-160, 1998

73. Tower SS: Pyramidal lesion in the monkey. Brain 63:36-90, 1940

74. Uribe J, Green BA, Vanni S, Moza K, Guest JD, Levi AD: Acute traumatic central cord syndrome-experience using surgical decompression with open-door expansile cervical laminoplasty. Surg Neurol 63:505-510, 2005

75. Vaccaro AR, Falatyn SP, Flanders AE, Balderston RA, Cotler JM: Magnetic resonance evaluation of the intervertebral disc, spinal ligaments, and spinal cord before and after closed traction-reduction of cervical spine dislocations. Spine 24:12101217, 1999

76. Vaccaro AR, Hulbert RJ, Patel AA, Fisher C, Dvorak M, Lehman RA, et al: The subaxial cervical spine injury classification system: a novel approach to recognize the importance of morphology, neurology, and integrity of the disco-ligamentous complex. Spine 32:2365-2374, 2007

77. Wallenberg A: Anatomischer Befund in einem als "acute Bulbärraffection (Embolie der Art. cerebellar post. inf. sinistr.?)" beschriebenen Falle. Eur Arch Psychiatry Clin Neurosci 34:923-959, 1901

78. White AA, Southwick WO, Panjabi MM: Clinical instability in the lower cervical spine: a review of past and current concepts. Spine 1:15-27, 1976

79. Yamazaki T, Yanaka K, Fujita K, Kamezaki T, Uemura K, Nose T: Traumatic central cord syndrome: analysis of factors affecting the outcome. Surg Neurol 63:95-99, 2005

Manuscript submitted July 14, 2008.

Accepted August 14, 2008.

Address correspondence to: Bizhan Aarabi, M.D., F.R.C.S.C., Department of Neurosurgery, University of Maryland School of Medicine, 22 South Greene Street, Suite S-12-D, Baltimore, Maryland 21201 email: baarabi@smail.umaryland.edu. 